\title{
The Woven EndoBridge Device for the Treatment of Intracranial Aneurysms: Initial Clinical Experience within an Australian Population
}

Jay Gajera, BSc, $\mathrm{MD}^{1}$, Julian Maingard, BBiomedSci, MBBS, FRANZCR, EBIR ${ }^{2,3,4}$, Michelle Foo, $\mathrm{MBBS}^{2}$, Yifan Ren, $\mathrm{MD}^{2}$, Anthony Lamanna, $\mathrm{MD}^{2}$, Daniel Nour, $\mathrm{MBBS}^{5}$, Jonathan Hall, MBBS, FRANZCR 5 , Dylan Kurda, MD, FRANZCR, EBIR ${ }^{6}$, David Tan, MBBS , Shivendra Lalloo, MBChB, MSc, FC Rad, FRANZCR, EBIR ${ }^{6}$, Ramon Martin Francisco Bañez, MD, FRANZCR ${ }^{3}$, Jeremy Russell, BSc/BE(Hons), MBBS(Hons), FRACS ${ }^{8}$, Lee-Anne Slater, MBBS(Hons), MMed, FRANZCR, CCINR 3 , Ronil Vikesh Chandra, MBBS, MMed, FRANZCR, CCINR 3 , Winston Chong, MBBS, FRANZCR, CCINR 3 , Ashu Jhamb, MBBS (Hons), FRANZCR, CCINR, EBIR ${ }^{5}$, Duncan Mark Brooks, MBBS, FRANZCR, CCINR, EBIR ${ }^{2}$, Hamed Asadi, MD, PhD, FRANZCR, CCINR, EBIR, FCIRSE, EBNI ${ }^{2,3,6,7,8}$

${ }^{1}$ Department of Radiology, Royal North Shore Hospital, Sydney, NSW, Australia

${ }^{2}$ Department of Radiology, Interventional Neuroradiology Service, Austin Health, Melbourne, VIC, Australia

${ }^{3}$ Interventional Neuroradiology Unit, Monash Imaging, Monash Health, Melbourne, VIC, Australia

${ }^{4}$ School of Medicine, Deakin University, Waurn Ponds, VIC, Australia

${ }^{5}$ Department of Radiology, Interventional Neuroradiology Service, St. Vincent's Hospital, Melbourne, VIC, Australia

${ }^{6}$ Department of Medical Imaging, Interventional Neuroradiology Service, The Canberra Hospital, ACT Health, Canberra, NSW, Australia

${ }^{7}$ Department of Neurosurgery, Royal Hobart Hospital, Hobart, TAS, Australia

${ }^{8}$ Department of Neurosurgery, Interventional Neuroradiology Service, Austin Health, Melbourne, VIC, Australia

Purpose: Advances in endovascular technology have expanded the treatment options for intracranial aneurysms. Intrasaccular flow diversion is a relatively new technique that aims to disrupt blood inflow at the neck of the aneurysm, hence promoting intrasaccular thrombosis. The Woven EndoBridge device (WEB; MicroVention, Aliso Viejo, CA, USA) is an US Food and Drug Administration approved intrasaccular flow diverter for wide-necked aneurysms. We report the early interim clinical and radiological outcomes of patients with both ruptured and unruptured intracranial aneurysms (IAs) treated using the WEB device in an Australian population.

Materials and Methods: A retrospective analysis was done of patients with ruptured or unruptured IAs who received treatment with WEB across 5 Australian neuroendovascular referral centers between May 2017 and November 2020. Angiographic occlusion was assessed with time-of-flight magnetic resonance angiography. Complications were recorded and clinical outcomes were assessed using the modified Rankin scale at follow-up.

Results: In total, 66 aneurysms were treated in 63 patients, with successful deployment of the WEB device in $98.5 \%$ ( $n=65)$. Eighteen (26.9\%) ruptured aneurysms were included. Failure of deployment occurred in a single case. Adjunct coiling and/or stenting was performed in 20.9\% ( $n=14$ ) cases. Sixty-two patients with 65 aneurysms using a WEB device were followed up (mean=9.1 months), and $89.4 \%$ of these had complete aneurysm occlusion while $1.5 \%$ remained patent. Functional independence was achieved in 93.5\% of cases.

Conclusion: Early results following the use of WEB devices in Australia demonstrate safety and adequate aneurysm occlusion comparable to international literature.

Key Words: Intracranial aneurysm; Endovascular procedures; Woven EndoBridge device; WEB; Intrasaccular; Flow diversion

\section{Correspondence to: Jay Gajera, BSc, MD Department of Radiology, Royal North Shore Hospital, Reserve Road, St Leonards, Sydney, NSW 2065, Australia \\ Fax: +61-3-9496-5431 \\ E-mail: jaygajera@gmail.com}

Received: September 15, 2021

Revised: January 5, 2022

Accepted: January 16, 2022

\begin{abstract}
Copyright $\odot 2022$ Korean Society of Interventional Neuroradiology

This is an Open Access article distributed under the terms of the Creative Commons Attribution Non-Commercial License (http://creativecommons.org/licenses/by-nc/4.0) which permits unrestricted non-commercial use, distribution, and reproduction in any medium, provided the original work is properly cited.
\end{abstract}




\section{INTRODUCTION}

Intrasaccular flow diversion has an established role in the management of intracranial aneurysms. Ruptured intracranial aneurysms (IAs) are the most common cause of spontaneous subarachnoid hemorrhage (SAH). The prevalence of unruptured IAs varies from 3-5\%; and whilst rupture risk is related to aneurysm size and location with the majority remaining unruptured, in cases of rupture causing $\mathrm{SAH}$, patients are at high risk of significant morbidity with a mortality rate of up to $50 \%{ }^{2}$ After the International Subarachnoid Hemorrhage Trial (ISAT) demonstrated higher disability-free survival rates in patients who received endovascular treatment compared to neurosurgical clipping, both ruptured and unruptured aneurysm treatment continues to shift towards endovascular coiling. ${ }^{3}$ Since ISAT, advances in endovascular technology and techniques have expanded the armamentarium available to the neurointerventionist. Balloon-assisted and stent-assisted approaches permit treatment of complex aneurysms previously deemed untreatable using endovascular techniques, such as those with difficult morphology or in difficult locations. More recently, flow diverting stents and various scaffolding devices allow the treatment of giant and wide-necked aneurysms with greater effectiveness. ${ }^{4}$ Intrasaccular flow diversion is a more novel technique that disrupts inflow at the neck of the aneurysm, promoting subsequent intrasaccular thrombosis. The Woven EndoBridge device (WEB; MicroVention, Aliso Viejo, CA, USA) is a US Food and Drug Administration approved intrasaccular flow diverter for wide-necked aneurysms. Early meta-analysis data demonstrated a good safety profile, with intermediate-term complete and adequate occlusion rates of 39\% (26-52\%) and 85\% (78-91\%) respectively. ${ }^{5}$ Following this, the multicenter, prospective, single-arm WEB-IT trial reported a technical success rate of $98.7 \%$, with only 1 primary safety event $(0.7 \%)$ and adequate occlusion in $84.6 \%$ of patients at 12 months. ${ }^{6,7}$

Data from 3 Good Clinical Practice studies including WEBCAST, FRENCH Observatory, and WEBCAST-2 with a pooled cohort of 168 patients with 169 wide-necked aneurysms ( $\geq 4 \mathrm{~mm}$ ) demonstrated complete occlusion in $52.9 \%$ and adequate occlusion in $79.1 \%$ after 1 year. A neck remnant was seen in $26.1 \%$ of participants and an aneurysm remnant in $20.9 \%$. Retreatment was performed in $6.9 \%$ of cases. ${ }^{8}$ These results compared favorably to pooled results for endovascular coiling of wide-necked aneurysms in 2,446 patients, with 2,556 aneurysms from 38 studies with a near-complete occlusion rate of $74.5 \%$ with retreatment rates of $5.8 \%{ }^{9}$

In Australia, there has been limited implementation of WEB treatment limited to a few Neurointervention centers, leading to substantial institutional and practitioner variation in the management of candidate intracranial aneurysms as well as the follow-up and surveillance of aneurysms treated with WEB. Whether this influences patient outcomes is unknown, although it represents a major knowledge gap in practice. This multicenter study is the first to report the initial clinical experience and early interim results of the WEB device when used to treat ruptured and unruptured aneurysms in a large series within an Australian population.

\section{MATERIALS AND METHODS}

\section{Population}

A retrospective analysis was performed across 5 Australian tertiary neuroendovascular referral centers, with inclusion of patients with ruptured and unruptured intracranial aneurysms treated with the WEB device between May 2017 and November 2020. This study was approved by the institutional human research ethics committee. As specific patient information such as age or sex is not included, informed consent for publication was not required. All procedures were performed by experienced neurointerventionists (JM, DK, SL, RMFB, LS, RC, WC, AJ, DMB, and HA) and treatment decisions were made by a multidisciplinary team consisting of neurointerventionists and neurosurgeons after discussion with the patient.

Wide-necked aneurysms (i.e., neck width $>4 \mathrm{~mm}$ and/or dome-to-neck ratio $>2$ ) were considered for treatment if the overall aneurysm morphology and location (i.e., lesion axis relative to parent vessel) appeared amenable to WEB deployment. Aneurysm sizes with a neck width of 3-10 mm and height between 3-10.5 mm were eligible to be treated with WEB and were able to accommodate the available device sizes smallest: WEB 17 single-layer ( $\mathrm{L}$, $3 \times 2 \mathrm{~mm}$ diameter) to largest: WEB 11 single-layer sphere (SLS, 11×9.6 mm diameter). With regards to aneurysm shape, the WEB systems are spherical (SLS) or cylindrical (SL) in shape, therefore unilobular aneurysms with spherical, cylindrical, or ovoid-shaped morphology are ideal for WEB deployment. The treatment approach was at the discretion of the treating neurointerventionist, depending on individual anatomical considerations, 
and aneurysms with unfavorable morphology or dimensions outside the available device sizes were excluded.

\section{Device}

The WEB device is a braided nitinol wire structure of various shapes and sizes. Both SL and SLS designs are available, ranging from SL $4 \times 3 \mathrm{~mm}$ smallest to $11 \times 9 \mathrm{~mm}$ largest; SLS diameter 4 to $11 \mathrm{~mm}$, height 2.6 to $9.6 \mathrm{~mm}$. Proximal and distal platinum markers assist in visualization during deployment. The WEB device has increased metal coverage at its base (almost $100 \%$ at its center) ${ }^{10}$ resulting in a smooth mesh surface that diverts flow from the parent vessel away from the aneurysmal sac. Postoperatively, if no WEB protrusion is evident and no other stenting was performed, the patient may be treated with a single antiplatelet agent (aspirin) for 5 to 6 weeks, thus potentially avoiding the need for prolonged dual antiplatelet therapy. ${ }^{11}$ These features make the WEB device a suitable treatment option for both ruptured and unruptured aneurysms. ${ }^{12}$

All procedures were performed as per conventional aneurysm coil treatment under general anesthesia, procedural intravenous heparin, and with varying dual antiplatelet loading regimens in elective cases. Continuous heparinized saline flush with or without nimodipine was used during the procedure. Triaxial access was obtained using a long guidesheath in the proximal internal carotid, subclavian, or vertebral artery, a distal access catheter in the intracranial internal carotid artery (ICA) or vertebral artery, and a microcatheter within the aneurysm. The device is deployable from a microcatheter with inner diameters ranging from 0.021 to 0.033 inch, depending on the size and shape of the device, which was selected at the discretion of the treating neurointerventionist. The WEB device was sized based on width and dome height measurements obtained during 3D digital subtraction angiography using a continuous column of contrast via an injecting pump. The device was generally oversized by approximately $1 \mathrm{~mm}$ to ensure close apposition of the device along the aneurysm wall. During deployment, the WEB device opens up such that the base of the device is retracted to lie across the neck of the aneurysm. Control angiography is performed to confirm appropriate placement and to check for platelet aggregation prior to release of the device. Final angiography confirms aneurysm occlusion.

\section{Anatomical Outcome}

Immediate angiographic occlusion was graded at the time of the procedure by the treating neurointerventionist as per the WEB occlusion scale (WOS) ${ }^{10}$ or modified Raymond-Roy occlusion classification (mRROC). ${ }^{13}$ The WOS is an angiographic assessment scale for reporting aneurysm occlusion achieved with intrasaccular mesh implants. WOS A\&B indicate complete occlusion without an angiographically visible collection of contrast within the marker recess. Residual neck (WOS C) is defined as the presence of contrast in contact with the aneurysmal neck that does not contact the wall of the aneurysmal sac or the inside of the WEB device, while a residual aneurysm (WOS D) is defined as apparent contrast in contact with the aneurysmal sac or inside the WEB device. The mRROC was employed when evaluating coiled aneurysms and is defined as class I (complete obliteration), class II (residual neck), class IIla (residual aneurysm with contrast within coil interstices), or class IIIb (residual aneurysm with contrast along aneurysm wall). All patients had early (within 1 week of deployment) and mid-term follow up (mean 9.1 months) with magnetic resonance imaging (MRI) including magnetic resonance angiography (MRA) with 3D time-offlight (TOF) technique, which were independently reviewed using multiplanar reformats by experienced neurointerventionists, who were blinded to treatment approaches and outcomes.

\section{Clinical Outcome}

Clinical outcome was assessed using the modified Rankin scale (mRS) at follow-up within 6 weeks following treatment. Complications were recorded in the procedural report and were readily available for review.

\section{RESULTS}

A total of 67 aneurysms in 64 patients were identified with attempted WEB treatment with an overall successful deployment of the WEB device in $98.5 \%$ ( $n=66$ ) of cases. Follow-up data were available for 65 aneurysms in 62 patients in our retrospective analysis. Baseline population characteristics are outlined in Table 1.

The median age was 63 (range 28-87) years, and most patients were female (75\%). Eighteen (26.9\%) ruptured aneurysms were included, most of which were World Federation of Neurosurgical Surgeons grade 1 presentations (12 of 18, 66.7\%). Most aneurysms were in the anterior circulation ( $n=37$, 55.2\%). Three middle cerebral artery (MCA) bifurcation an- 
eurysms were also included. The median aneurysm dome height was $5.8 \mathrm{~mm}$ (range 2.8-14 mm) with a median neck width of $3.5 \mathrm{~mm}$ (range 1.6-9.9 mm). Thirteen patients (20\%) had undergone prior treatment for intracranial aneurysms. Three patients received 2 WEB devices each. In 1 of these patients, 2 WEB devices were deployed during the same procedure in distal pericallosal artery and anterior communicating artery (ACOM) aneurysms.

Table 2 outlines periprocedural antiplatelet use. Antiplate-

Table 1. Baseline demographics and aneurysm location, size, and morphology

\begin{tabular}{|c|c|c|c|}
\hline \multicolumn{3}{|c|}{ Population characteristics } & Value \\
\hline \multicolumn{3}{|l|}{ Age (y) } & $63(28-87)$ \\
\hline \multicolumn{3}{|l|}{ Sex, female } & $48(75.0)$ \\
\hline \multicolumn{3}{|c|}{ Past history of previously treated aneurysm } & $13(20.0)$ \\
\hline \multirow{6}{*}{$\begin{array}{l}\text { Ruptured } \\
\text { aneurysm }\end{array}$} & Total & & $18(26.9)$ \\
\hline & WFMS grade & 1 & $12(17.9)$ \\
\hline & & 2 & $3(4.5)$ \\
\hline & & 3 & $0(0.0)$ \\
\hline & & 4 & $0(0.0)$ \\
\hline & & 5 & $3(4.5)$ \\
\hline \multirow{4}{*}{\multicolumn{2}{|c|}{ GCS at presentation }} & 15 & $57(86.4)$ \\
\hline & & 14 & $0(0.0)$ \\
\hline & & 13 & $4(6.1)$ \\
\hline & & 12 or less & $5(7.6)$ \\
\hline \multirow{10}{*}{$\begin{array}{l}\text { Aneurysm } \\
\text { location }\end{array}$} & \multirow{5}{*}{$\begin{array}{l}\text { Anterior } \\
\text { circulation }\end{array}$} & Total (anterior) & $37(55.2)$ \\
\hline & & $\begin{array}{l}\text { Carotid (terminus/ } \\
\text { paraopth) }\end{array}$ & $17(25.4)$ \\
\hline & & ACOM & $14(20.9)$ \\
\hline & & MCA & $4(6.0)$ \\
\hline & & ACA (pericallosal) & $2(3.0)$ \\
\hline & \multirow{5}{*}{$\begin{array}{l}\text { Posterior } \\
\text { circulation }\end{array}$} & Total (posterior) & $30(41.8)$ \\
\hline & & Basilar & $20(28.4)$ \\
\hline & & PCOM & $6(9.0)$ \\
\hline & & SCA & $3(3.0)$ \\
\hline & & PCA & $1(1.5)$ \\
\hline \multicolumn{3}{|c|}{ Aneurysm dome width (mm) } & $5.5(3-12.2)$ \\
\hline \multicolumn{3}{|c|}{ Aneurysm dome height (mm) } & $5.8(2.8-14)$ \\
\hline \multicolumn{3}{|c|}{ Aneurysm neck width (mm) } & $3.5(1.6-9.9)$ \\
\hline
\end{tabular}

Values are presented as median (range) or number (\%).

WFNS, World Federation of Neurosurgical Surgeons; GCS, Glasgow coma scale; ACOM, anterior communicating artery; MCA, middle cerebral artery; ACA, anterior cerebral artery; PCOM, posterior communicating artery; SCA, superior cerebellar artery; PCA, posterior cerebral artery. let regimens varied and were dependent on operator preference, patient compliance, and the presence of antiplatelet resistance as determined by the VerifyNow P2Y12 assay (Accumetrics, San Diego, CA, USA). One patient was converted to Prasugrel after platelet function testing and high platelet reactivity unit values were noted on Clopidogrel. Eighteen patients who presented with ruptured aneurysms were not pre-medicated with antiplatelet agents. Failure of deploy-

Table 2. Periprocedural antiplatelet use, procedural outcomes, and immediate angiographic occlusion

\begin{tabular}{|c|c|c|}
\hline \multicolumn{2}{|l|}{ Procedural technique } & \multirow{2}{*}{$\frac{\text { Value }}{19(28.8)}$} \\
\hline Preprocedural & Nil & \\
\hline antiplatelet agents & Any & $47(71.2)$ \\
\hline & Aspirin/clopidogrel & $42(63.6)$ \\
\hline & Aspirin & $2(3.0)$ \\
\hline & Clopidogrel & $2(3.0)$ \\
\hline & Aspirin/prasugrel & $1(1.5)$ \\
\hline \multirow{5}{*}{$\begin{array}{l}\text { Intraprocedural } \\
\text { anticoagulant +/- } \\
\text { antiplatelet agents }\end{array}$} & Nil & $3(4.5)$ \\
\hline & Any & 63 (95.5) \\
\hline & Heparin & $57(86.4)$ \\
\hline & Heparin/IV aspirin & $5(7.6)$ \\
\hline & Heparin/intergrillin & $1(1.5)$ \\
\hline \multirow{6}{*}{$\begin{array}{l}\text { Postprocedural } \\
\text { antiplatelet agents }\end{array}$} & Nil & $1(1.5)$ \\
\hline & Any & $65(98.5)$ \\
\hline & Aspirin & $54(81.8)$ \\
\hline & Aspirin/clopidogrel & $8(12.1)$ \\
\hline & Aspirin/prasugrel & $1(1.5)$ \\
\hline & Clopidogrel & $2(3.0)$ \\
\hline \multicolumn{2}{|l|}{ Device Failure } & $1(1.5)$ \\
\hline \multirow[t]{5}{*}{ Adjunct device used } & Nil & $50(74.6)$ \\
\hline & Any & $17(25.4)$ \\
\hline & Coils & $11(16.4)$ \\
\hline & Balloon assisted & $3(4.5)$ \\
\hline & LVIS stent & $3(4.5)$ \\
\hline \multicolumn{2}{|c|}{ Need for resizing WEB device } & $4(6.0)$ \\
\hline \multirow[t]{3}{*}{$\begin{array}{l}\text { Immediate modified } \\
\text { WOS }\end{array}$} & $\begin{array}{l}\text { Complete occlusion } \\
\text { (WOS A\&B) }\end{array}$ & $58(86.6)$ \\
\hline & Residual neck (WOS C) & $6(9.2)$ \\
\hline & $\begin{array}{l}\text { Residual aneurysm } \\
\text { (WOS D) }\end{array}$ & $2(3.1)$ \\
\hline Immediate mRROC & RAY $3 A$ & $1(1.5)$ \\
\hline
\end{tabular}

Values are presented as number (\%).

Nil, none; IV, intravenous; LVIS, Low-profile visualized intraluminal support device (MicroVention Inc., Aliso Viejo, CA, USA); WOS, WEB occlusion scale; mRROC, modified Raymond-Roy occlusion class. 
ment was encountered in a single case of an unruptured $7 \mathrm{~mm}$ posterior inferior cerebellar artery aneurysm, which was subsequently converted to endovascular coiling during the procedure due to difficult aneurysm neck access precluding safe positioning of the WEB device. Adjunct coiling and/or stenting was performed in 14 cases (20.9\%). Immediate complete angiographic occlusion was achieved in $88.1 \%$ $(n=59)$ of cases (WOS A\&B in 58 patients and mRROC RAY 3A in a single case in which coil embolization alone was performed).

\section{Clinical Outcomes}

Table 3 outlines complications encountered, the need for retreatment, follow-up time, clinical outcome, and early/ interim angiographic outcome in our cohort. Functional independence (mRS 0-2) at follow-up was achieved in 58 patients (93.5\%); 13 patients who presented with ruptured aneurysms were functionally independent at clinical follow-up. Three patients had an mRS of 1 at follow-up; a single treated unruptured right posterior communicating artery aneurysm had a persistent third cranial nerve palsy at clinical follow-up and a second patient suffered a delayed stroke to an alternate vascular territory after treatment of the index right superior cerebellar artery aneurysm with mild residual deficit at follow-up. Treatment of an 8.3×6.3 mm ACOM aneurysm with a $6.2 \mathrm{~mm}$ neck was complicated by pericallosal artery wire perforation and acute SAH; however, this patient was functionally independent at follow up (mRS 0).

One patient with an unruptured $3 \times 4 \mathrm{~mm}$ left ICA terminus aneurysm suffered an acute clinical deterioration post WEB deployment secondary to a large intraparenchymal hemorrhage distal to the treated aneurysm. The patient had previously had right MCA and right ICA aneurysms treated 6 weeks prior (with a WEB and coil embolization respectively) and had been on dual antiplatelet therapy after deployment of a right ICA stent during the first procedure. Additional left anterior temporal artery and right $\mathrm{M} 1$ aneurysms were treated during the same session. The exact cause of this was unknown and ultimately resulted in significant permanent neurological morbidity (mRS 5). Another patient with a treated wide-necked $7 \mathrm{~mm}$ basilar tip aneurysm subsequently died following the rupture of a separate untreated giant ACOM aneurysm several weeks after treatment (mRS 6).

\section{Radiological Outcomes}

A total of 62 patients with 65 aneurysms with a WEB device were followed up with multisequence MRI and non-contrast TOF MRA between 2 weeks and 31 months post-procedure. Fifty-nine of these had complete aneurysm occlusion (WOS A\&B: 89.4\%) and 1 remained patent (WOS D: 1.5\%). Adequate occlusion was achieved in 1 patient with failed WEB deployment in which multiple soft Medtronic coils were used (modified Raymond-Roy occlusion RAY 3A) on their most recent follow-up imaging. There were initially 2 patients with WOS D occlusion and they both had identifiable sizing issues

Table 3. Complications, need for retreatment, follow up time, clinical outcomes, and early/interim angiographic outcomes

\begin{tabular}{|c|c|c|}
\hline \multicolumn{2}{|c|}{ Morbidity and mortality } & \multirow{2}{*}{$\frac{\text { Value }}{57(89.1)}$} \\
\hline Complications & Nil & \\
\hline & Any & $7(10.9)$ \\
\hline & Thromboembolism & $4(6.3)$ \\
\hline & $\begin{array}{l}\text { Perforation/subarachnoid } \\
\text { hemorrhage }\end{array}$ & $1(1.6)$ \\
\hline & Intracerebral hemorrhage & $1(1.6)$ \\
\hline & $\begin{array}{l}\text { Hydrocephalus requiring } \\
\text { VP-shunt insertion }\end{array}$ & $1(1.6)$ \\
\hline & Mortality & $1(2)$ \\
\hline & Procedure related mortality & $0(0)$ \\
\hline \multirow{2}{*}{$\begin{array}{l}\text { Need for } \\
\text { retreatment }\end{array}$} & Not required & $64(98.5)$ \\
\hline & Retreatment performed & $1(1.5)$ \\
\hline \multirow{3}{*}{$\begin{array}{l}\text { Follow-up time } \\
\text { (mo) }\end{array}$} & Mean & 9.1 \\
\hline & Minimum & 0.5 \\
\hline & Maximum & 31.3 \\
\hline \multirow[t]{9}{*}{ Follow-up mRS } & $\mathrm{mRS}(0-2)$ & $58(93.5)$ \\
\hline & 0 & $54(87.1)$ \\
\hline & 1 & $3(4.8)$ \\
\hline & 2 & $1(1.6)$ \\
\hline & mRS (3-6) & $4(6.5)$ \\
\hline & 3 & $3(4.8)$ \\
\hline & 4 & $1(1.6)$ \\
\hline & 5 & $0(0)$ \\
\hline & 6 & $0(0)$ \\
\hline \multirow[t]{3}{*}{$\begin{array}{l}\text { Follow-up } \\
\text { modified wOS }\end{array}$} & $\begin{array}{l}\text { Complete occlusion } \\
\text { (WOS A\&B) }\end{array}$ & $59(89.4)$ \\
\hline & Residual neck (WOS C) & $5(7.6)$ \\
\hline & Residual aneurysm (WOS D) & $1(1.5)$ \\
\hline Follow-up mRROC & RAY 2A & $1(1.5)$ \\
\hline
\end{tabular}

Values are presented as number (\%).

Nil, none; VP-shunt, ventriculo-peritoneal shunt; mRS, modified Rankin scale; WOS, WEB occlusion scale; mRROC, modified Raymond-Roy occlusion class. 
during deployment. Retreatment using stent-assisted coiling was successfully performed in 1 of these patients who went on to achieve WOS B on subsequent imaging. The second patient improved to WOS C on their most recent imaging.

\section{DISCUSSION}

Our results are comparable to a previously published case series with an overall technical success rate of $98.5 \%$, with only a single patient showing an unfavorable angle that precluded safe device deployment. Pierot et al. ${ }^{8}$ demonstrated a technical success rate of $96.4 \%$ with reported causes for failure including device protrusion into the parent vessel, lack of appropriate device sizing, and failure to deploy the device. Similarly, the WEB-IT trial reported a technical success rate of $98.7 \%$ quoting similar reasons. ${ }^{7}$ Overall, our adequate occlusion rate was $90.7 \%$, which is similar to international standards. ${ }^{5,8}$ The WEB device can be combined with traditional coil embolization particularly if there is concern about daughter lobes or a point of recent rupture necessitating the need to secure the aneurysm dome prior to occluding the aneurysm neck.

Of 18 ruptured aneurysms, there was 1 mortality; and of the remaining 17 at mid-term follow-up, 14 achieved WOS A\&B (82.4\%), 2 were WOS C (11.8\%), and 1 was WOS D (5.9\%). This is comparable to the reported literature, as Youssef et al. $^{14}$, in a study involving 48 patients with ruptured IAs, reported adequate occlusion in $92.3 \%$ at a median follow up of 5.5 months, and Cortez et al. ${ }^{15}$, in a study of 91 patients with ruptured IAs, demonstrated $80 \%$ adequate occlusion at a mean follow up of 3.4 months. A subsequent meta-analysis by Essibayi et al. ${ }^{16}$ pooled 487 patients with 496 ruptured aneurysms treated with WEB, reporting an adequate occlusion rate of $87.3 \%$. The single mortality in our series was unrelated to WEB deployment. The patient presented with a rupture of a second giant $19 \mathrm{~mm}$ ACOM aneurysm 1 month after treatment of a ruptured $7 \mathrm{~mm}$ wide-necked basilar tip aneurysm.

A second patient suffered a delayed large intraparenchymal hemorrhage with permanent morbidity (mRS of 5 at 3 months) after treatment of several aneurysms in a single session including deployment of an SL 5×3 WEB into a $5 \mathrm{~mm}$ left ICA terminus aneurysm and concomitant coiling of left anterior temporal artery and right $\mathrm{M} 1$ aneurysms.

The use of endosaccular coiling for many intracranial aneurysms gained acceptance following the ISAT trial after it demonstrated an increased disability-free survival at 7 years compared to neurosurgical clipping. ${ }^{3}$ However, this trial was conducted many years ago and several novel techniques and devices have since been developed, further encouraging the use of minimally invasive treatments. In particular, these advances have made the endovascular treatment of wide-necked aneurysms safer with low periprocedural morbidity and mortality. ${ }^{5}$ Pooled data from 15 uncontrolled studies reported complete or near-complete occlusion rates of $74.5 \%$ and retreatment rates of $5.8 \%$ with or without stent assistance after at least 6 months of angiographic follow-up. ${ }^{5}$ Pierot et al. ${ }^{17}$ demonstrated a retreatment rate of $9.3 \%$ at 2 years in a combined analysis of 3 prospective European trials, with the majority of patients requiring retreatment in their first year.

As an intrasaccular flow diverter, the WEB device allows the treatment of more complex wide-necked aneurysms which are less suitable for other endovascular devices. One-year retreatment rates are low, ranging from $6 \%^{5}$ to $7.1 \%,{ }^{8,17}$ and are similar to those treated with coiling (5.2\%). ${ }^{9}$ Additionally, the WEB device can be used to treat aneurysms of differing geometry and locations given its range of shapes and sizes. Other benefits of the WEB device include shorter procedural times attributed to single-step treatment in most selected cases. Whether this translates into lower overall implant cost when compared to stent-assisted coiling is yet to be determined in the Australian context.

Wide-necked bifurcation aneurysms have traditionally been more difficult to treat endovascularly. A meta-analysis of 36 studies found that factors related to shortterm angiographic obliteration include unruptured status, location in the anterior circulation, a medium neck (4-9.9 mm), use of newer-generation WEB, and treatment without additional devices. ${ }^{18}$ Reported rates of 12 -month complete occlusion rates after using coiling and stent-assisted coiling for the treatment of wide-necked aneurysms are $27.1 \%$ and $45.7 \%$, respectively. ${ }^{19}$ These results are inferior to rates of $54.8 \%, 53.8 \%$, and $52.9 \%$ that have been reported when using the WEB device. ${ }^{6-8}$ Stent-assisted coiling can offer high long-term complete aneurysmal occlusion; however, 12-month morbidity and mortality rates reported with its use in wide-necked aneurysms (7.5\%) are considerably higher than that of coiling (1.5\%) with WEB..$^{19}$ The multicenter Canadian-led RISE trial—a randomized controlled trial comparing intra-saccular flow diversion versus conventional management (surgical or endovascular) is currently underway and 
seeks to determine whether intravascular flow diversion leads to better long-term outcomes. ${ }^{20}$

Known complications of the WEB device include failed deployment, thromboembolic events, and intracranial hemorrhage either from aneurysm rupture or vessel perforation. Goertz et al. ${ }^{21}$ report a lower aspect ratio and an increased width to height ratio are significant risk factors for procedural complications. Our thromboembolism rate of $6.3 \%$ was lower than previously reported results, which range from $7.4 \%$ to $14.4 \%{ }^{5,7,8}$ It is also within the reported thromboembolism rate in large coiling series (5.4\% for unruptured aneurysms and $20.8 \%$ for ruptured aneurysms). ${ }^{22,23}$ Reported rates of procedural intracranial hemorrhage with WEB are low. WEBIT and Pierot et al. ${ }^{8}$ reported intracranial hemorrhage rates of $1.2 \%$ and $0.6 \%$, respectively. ${ }^{7}$ Our results are similar, and these are comparable to those published with coiling. ${ }^{22,23}$ Long-term morbidity is also low with a reported 12-month procedure-related morbidity rate of $1.3 \%$.

Like previous studies, we encountered no periprocedural or postprocedural deaths suggesting that the mortality risk associated with WEB is low. This high safety profile is likely to continue into the long-term, with WEB-IT and Pierot et al. $^{8}$ reporting 12-month procedure-related mortality rates of $0 \%$ and $1.3 \%$, respectively. To our knowledge, delayed aneurysm rupture following treatment with WEB has not been reported.

\section{Limitations}

The present analysis is limited by its retrospective nature and potential for patient selection bias. The small cohort of patients is heterogeneous with aneurysms varying in location, morphology, and clinical presentation limiting generalizability. Furthermore, the short interval for follow-up for many of these patients may not account for delayed neck recanalization. Further long-term follow-up will be required. While all patients were followed up with MRI as per our standard post embolization protocol, it remains to be seen whether MRI is the most appropriate and accurate method in which to assess aneurysm occlusion after WEB deployment. While interobserver reproducibility was excellent for contrast-enhanced (CE)-MRA ( $\mathrm{K}=0.92 ; 95 \%$ confidence interval [95\% Cl], $0.76-1.00)$ and moderate $(\mathrm{K}=0.59 ; 95 \% \mathrm{Cl}, 0.30-0.88)$ for $3 \mathrm{D}$ TOF, Timsit et al. ${ }^{24}$ reported low sensitivity on both CE-MRA and 3D TOF MRA for remnant detection, with 3 out of 4 recurrences not detected on MRA and only fair inter-modality agreement with digital subtraction angiography (DSA). Sim- ilarly, Mine et al. ${ }^{25}$ reported that $40 \%$ of aneurysm remnants were not detected on CE-MRA. While MRA remains the standard for screening, like flow diversion and stent placement, 6-month or 1-year delayed DSA should be considered the gold standard for follow-up but is not necessarily practical due to the risks associated with more invasive testing. Despite these limitations, this study demonstrates that the use of the WEB device to treat intracranial aneurysms in Australia produces similar results to those seen internationally. This is particularly significant given the recent rise in use of WEB devices in the Australian population.

\section{CONCLUSION}

Early results following the use of WEB devices in Australia demonstrate safety and adequate aneurysm occlusion comparable to international literature.

\section{Acknowledgments}

All investigators freely volunteered their time towards this project. Department of Radiology, Austin Health, Melbourne, VIC, Australia. Department of Radiology, Monash Health, Melbourne, VIC, Australia. Department of Radiology, St. Vincent's Health, Melbourne, VIC, Australia. Department of Radiology, Canberra Hospital, ACT Health, Canberra, NSW, Australia. Department of Radiology, Royal Hobart Hospital, Hobart, TAS, Australia. Department of Radiology, Royal North Shore Hospital, Sydney, NSW, Australia.

\section{Fund}

None.

\section{Ethics Statement}

Low Negligible Risk Study, retrospective, approved by local institutional review board. As specific patient information such as age or sex is not included, Informed consent for publication is not required.

\section{Conflicts of Interest}

The authors have no conflicts to disclose.

\section{Author Contributions}

Concept and design: HA. Analysis and interpretation: JG, JM, and HA. Data collection: JG, YR, AL, DN, JH, DK, DT, SL, RMFB, $J R$, LS, RC, WC, AJ, DMB, and HA. Writing the article: JG and 
$J M$. Critical revision of the article: JG, JM, MF, YR, AL, DN, JH, $D K, D T, S L, R M F B, J R, L S, R C, W C, A J, D M B$, and HA. Final approval of the article: JM and HA. Statistical analysis: JG, MF, and HA. Overall responsibility: HA.

\section{ORCID}

Jay Gajera: https://orcid.org/0000-0003-2395-4520

Julian Maingard: https://orcid.org/0000-0001-8958-2411

Michelle Foo: https://orcid.org/0000-0001-8056-1163

Yifan Ren: https://orcid.org/0000-0001-6518-6828

Anthony Lamanna: https://orcid.org/0000-0003-0705-2252

Daniel Nour: https://orcid.org/0000-0002-0064-0775

Jonathan Hall: https://orcid.org/0000-0001-9927-1238

Dylan Kurda: https://orcid.org/0000-0002-1663-4185

David Tan: https://orcid.org/0000-0003-0180-6666

Shivendra Lalloo: https://orcid.org/0000-0002-9384-635X

Ramon Martin Francisco Bañez: https://orcid.org/0000-00023884-2807

Jeremy Russell: https://orcid.org/0000-0003-3692-120X

Lee-Anne Slater: https://orcid.org/0000-0002-1140-8664

Ronil Vikesh Chandra: https://orcid.org/0000-0001-7555-2297

Winston Chong: https://orcid.org/0000-0001-7645-2861

Ashu Jhamb: https://orcid.org/0000-0002-7097-1641

Duncan Mark Brooks: https://orcid.org/0000-0002-8914-2683

Hamed Asadi: https://orcid.org/0000-0003-2475-9727

\section{REFERENCES}

1. Vlak MH, Algra A, Brandenburg R, Rinkel GJ. Prevalence of unruptured intracranial aneurysms, with emphasis on sex, age, comorbidity, country, and time period: a systematic review and meta-analysis. Lancet Neurol 201 1;10:626-636

2. Nieuwkamp DJ, Setz LE, Algra A, Linn FH, de Rooij NK, Rinkel GJ. Changes in case fatality of aneurysmal subarachnoid haemorrhage over time, according to age, sex, and region: a meta-analysis. Lancet Neurol 2009;8:635-642

3. Molyneux AJ, Kerr RS, Yu LM, Clarke M, Sneade M, Yarnold JA, et al.; International Subarachnoid Aneurysm Trial (ISAT) Collaborative Group. International subarachnoid aneurysm trial (ISAT) of neurosurgical clipping versus endovascular coiling in 2143 patients with ruptured intracranial aneurysms: a randomised comparison of effects on survival, dependency, seizures, rebleeding, subgroups, and aneurysm occlusion. Lancet 2005;366:809-817

4. Jia ZY, Shi HB, Miyachi S, Hwang SM, Sheen JJ, Song YS, et al. Development of new endovascular devices for aneurysm treat- ment. J Stroke 2018;20:46-56

5. Asnafi S, Rouchaud A, Pierot L, Brinjikji W, Murad MH, Kallmes DF. Efficacy and safety of the Woven EndoBridge (WEB) device for the treatment of intracranial aneurysms: a systematic review and meta-analysis. AJNR Am J Neuroradiol 2016;37:2287-2292

6. Arthur AS, Molyneux A, Coon AL, Saatci I, Szikora I, Baltacioglu F, et al.; WEB-IT Study investigators. The safety and effectiveness of the Woven EndoBridge (WEB) system for the treatment of wide-necked bifurcation aneurysms: final 12-month results of the pivotal WEB Intrasaccular Therapy (WEB-IT) study. J Neurointerv Surg 2019;11:924-930

7. Fiorella D, Molyneux A, Coon A, Szikora I, Saatci I, Baltacioglu F, et al.; WEB-IT Study Investigators. Demographic, procedural and 30-day safety results from the WEB Intra-saccular Therapy study (WEB-IT). J Neurointerv Surg 2017;9:1191-1196

8. Pierot L, Moret J, Barreau X, Szikora I, Herbreteau D, Turjman F, et al. Safety and efficacy of aneurysm treatment with WEB in the cumulative population of three prospective, multicenter series. J Neurointerv Surg 2018;10:553-559

9. Zhao B, Yin R, Lanzino G, Kallmes DF, Cloft HJ, Brinjikji W. Endovascular coiling of wide-neck and wide-neck bifurcation aneurysms: a systematic review and meta-analysis. AJNR Am J Neuroradio/ 2016;37:1700-1705

10. Goyal N, Hoit D, DiNitto J, Elijovich L, Fiorella D, Pierot $L$, et al. How to WEB: a practical review of methodology for the use of the Woven EndoBridge. J Neurointerv Surg 2020;12:512-520

11. Pierot $L$. Ten years of clinical evaluation of the Woven EndoBridge: a safe and effective treatment for wide-neck bifurcation aneurysms. Neurointervention 2021;16:211-221

12. Clajus C, Strasilla C, Fiebig T, Sychra V, Fiorella D, Klisch J. Initial and mid-term results from 108 consecutive patients with cerebral aneurysms treated with the WEB device. J Neurointerv Surg 2017:9:411-417

13. Mascitelli JR, Moyle H, Oermann EK, Polykarpou MF, Patel AA, Doshi AH, et al. An update to the Raymond-Roy Occlusion Classification of intracranial aneurysms treated with coil embolization. J Neurointerv Surg 2015;7:496-502

14. Youssef PP, Dornbos lii D, Peterson J, Sweid A, Zakeri A, Nimjee SM, et al. Woven EndoBridge (WEB) device in the treatment of ruptured aneurysms. J Neurointerv Surg 2021;13:443-446

15. Cortez GM, Akture E, Monteiro A, Arthur AS, Peterson J, Dornbos $D$, et al. Woven EndoBridge device for ruptured aneurysms: perioperative results of a US multicenter experience. J Neurointerv Surg 2021;13:1012-1016

16. Essibayi MA, Lanzino G, Brinjikji W. Safety and efficacy of the Woven EndoBridge device for treatment of ruptured intracrani- 
al aneurysms: a systematic review and meta-analysis. AJNR Am J Neuroradiol 2021;42:1627-1632

17. Pierot L, Moret J, Barreau X, Szikora I, Herbreteau D, Turjman F, et al. Aneurysm treatment with Woven EndoBridge in the cumulative population of 3 prospective, multicenter series: 2-year follow-up. Neurosurgery 2020;87:357-367

18. Zhang SM, Liu LX, Ren PW, Xie XD, Miao J. Effectiveness, safety and risk factors of Woven EndoBridge device in the treatment of wide-neck intracranial aneurysms: systematic review and meta-analysis. World Neurosurg 2020;136:e1-e23

19. Hetts SW, Turk A, English JD, Dowd CF, Mocco J, Prestigiacomo $C$, et al.; Matrix and Platinum Science Trial Investigators. Stent-assisted coiling versus coiling alone in unruptured intracranial aneurysms in the matrix and platinum science trial: safety, efficacy, and mid-term outcomes. AJNR Am J Neuroradiol 2014;35:698-705

20. Raymond J, Januel AC, lancu D, Roy D, Weill A, Carlson A, et al. The RISE trial: a randomized trial on Intra-saccular Endobridge devices. Interv Neuroradiol 2020;26:61-67

21. Goertz L, Liebig T, Siebert E, Herzberg M, Neuschmelting $H$,
Borggrefe J, et al. Risk factors of procedural complications related to Woven EndoBridge (WEB) embolization of intracranial aneurysms. Clin Neuroradiol 2020;30:297-304

22. Pierot L, Spelle L, Leclerc X, Cognard C, Bonafé A, Moret J. Endovascular treatment of unruptured intracranial aneurysms: comparison of safety of remodeling technique and standard treatment with coils. Radiology 2009;251:846-855

23. Pierot L, Cognard C, Anxionnat R, Ricolfi F; CLARITY Investigators. Ruptured intracranial aneurysms: factors affecting the rate and outcome of endovascular treatment complications in a series of 782 patients (CLARITY study). Radiology 2010;256:916923

24. Timsit C, Soize S, Benaissa A, Portefaix C, Gauvrit JY, Pierot L. Contrast-enhanced and time-of-flight MRA at 3T compared with DSA for the follow-up of intracranial aneurysms treated with the WEB device. AJNR Am J Neuroradio/ 2016;37:1684-1689

25. Mine B, Tancredi I, Aljishi A, Alghamdi F, Beltran M, Herchuelz M, et al. Follow-up of intracranial aneurysms treated by a WEB flow disrupter: a comparative study of DSA and contrast-enhanced MR angiography. J Neurointerv Surg 2016;8:615-620 